\title{
Research on the Optimized Management of Agricultural Machinery Allocation Path Based on Teaching and Learning Optimization Algorithm
}

\author{
Ye LIU, Luan SHI, Yang GAO, Chunyu KOU, Shuguo YANG, Li LIU*
}

\begin{abstract}
With the adjustment of agricultural industry structure and the acceleration of land transfer in our country, the appropriate management level of continuous, large scale and intensive farming has remarkably improved, which has put forward a higher requirement for the level of agricultural machinery. According to statistics, the comprehensive mechanization rate of farming, planting and harvesting of major crops in China has exceeded $70 \%$ in 2020 . However, the development level of mechanization in different provinces and regions is still unbalanced, so is the demand and supply of seasonal agricultural machinery operation. Cross regional operation of agricultural machinery is still a common occurrence. So a scientific, efficient and low-cost agricultural machinery allocation scheme is to be constructed so as to solve the imbalance of development level between regions of agricultural mechanization and the contradiction between supply and demand of agricultural machinery in operation seasons and to realize the rational allocation of agricultural machinery in cross regional operation. The allocation scheme can increase the machinery owners' income by improving the utilization rate and allocation cost of agricultural machinery. This study systematically analyzes and summarizes the allocation mode of agricultural machinery in the reclamation area, constructs relevant data models and solution methods, and ultimately comes to the effective solution of the operation relationship allocation model and path optimization model under different allocation modes of agricultural machinery based on TLBO optimization theory and method, which effectively solves the problem of rational and efficient allocation of agricultural machinery in cross regional operation of agricultural machinery.
\end{abstract}

Keywords: agricultural machinery scheduling and allocating; allocation path; teaching and learning optimization algorithm

\section{INTRODUCTION}

The level of agricultural mechanization represents the level of agricultural development in a country and region. In recent years, with the country's strong support and development of agricultural mechanization, my country's agricultural machinery coverage and modernization level have increased rapidly. However, at the same time, we should also realize that due to factors such as farming methods, farming area, crops, and economic development levels, there is an imbalance in the development level of domestic agricultural mechanization among regions. Areas with developed economically more modern farming methods have more agricultural machinery. The degree of agricultural mechanization is relatively high, and the level of agricultural production is relatively higher. The economically underdeveloped farming areas are more traditional. The development of agricultural mechanization is relatively slow, and the possession of agricultural machinery is relatively small, resulting in a relatively low level of agricultural production. From the perspective of national agricultural development, due to its advantages in organization, large-scale, and high industrialization, the agricultural reclamation has made a pioneering demonstration in the improvement of agricultural machinery. Taking Heilongjiang Land Reclamation as an example, the comprehensive mechanization rate of the cultivation and harvest of main crops in 2020 has reached $99.9 \%$, which has played an important role in the improvement of agricultural farming efficiency. However, while the number of agricultural mechanization is growing rapidly, we have also found that due to factors such as the concentration of agricultural production cycles, low utilization rate of agricultural machinery, the return on investment of agricultural machinery is not high. Nongovernmental allocation of agricultural machinery is relatively common, and there is a lack of effective agricultural machinery allocation plans. The low utilization rate of agricultural machinery has caused a certain degree of resource waste. Formulating effective agricultural machinery scheduling and allocating plans and methods comprehensively, enhances the sharing of agricultural machinery and realizes the economic benefits of rapid return on agricultural machinery investment. It is a problem that the agricultural machinery management department must solve.

According to the literature, foreign scholars were more interested in the optimization of agricultural machinery equipment and the optimization of operation paths. Sorensen et al. (2010) and Nikkilä et al. (2012) further optimized and perfected the agricultural information management model and architecture, and further simulated how to collect and report data through the agricultural information management system to improve the management efficiency of farm managers [1]. Sethanan (2016) believes that the planning of the operation path of the harvester has a great impact on improving the efficiency of sugarcane machinery harvesting. He designed a new particle encoding/decoding scheme that combines path planning with accessibility and segmentation harvesting constraints to solve the path planning of harvester [2]. Along with the reform of the rural economic system in China, agricultural machinery is widely used, and the optimization of agricultural machinery research has gradually emerged. Yao Jingfa (2020) proposed a simulated annealing algorithm based on Doppler and greedy strategy to optimize the operation path of agricultural machinery in terraced farmland, rectangular farmland and other different shapes [3].

The ant colony algorithm is also very effective in solving the research of multi-site and multi-agricultural machinery operation path. Cao Ruyue (2019) took the Zhuozhou experimental farm as an example, established a task sequence-planning model for agricultural machinery operations, and set up task sets with different numbers of blocks as tasks according to the actual operating blocks. With the continuous improvement and application of information technology, through the application of cloud 
technology and Internet of Things technology, the role of decision support systems in the scheduling and allocating of agricultural machinery has become more and more obvious. Scholars have studied the construction of the agricultural machinery scheduling and allocating system platform from different perspectives such as real-time display, agricultural machinery monitoring, and intelligent scheduling. Cao Huannan et al. (2020) designed an agricultural machinery appointment system in order to improve the scheduling level and the efficiency of agricultural machinery scheduling and distribution through App online appointment [4]. Jiang Nan (2020) introduced the neural network algorithm of particle swarm optimization into the process of agricultural machinery scheduling network security assessment, and verified its feasibility and reliability. The neural network algorithm using particle swarm optimization is more efficient for network security evaluation, and can meet the needs of the security situation evaluation of the agricultural machinery network dispatching system $[5,6]$.

Throughout the research situation at home and abroad, we found during the research of path planning algorithm, the traditional precise algorithm and heuristic algorithm are developed to the hybrid algorithm based on intelligent algorithm. As a new optimization method, intelligent algorithm has been widely used and developed rapidly in many optimization problems. The research and application of intelligent algorithms in dynamic, constrained, multiobjective, uncertain, discrete and other complex optimization problems are constantly enriched, and their application fields are constantly broadened. There has been in-depth research on the intelligent algorithm for the route optimization of agricultural machinery scheduling and allocating, but it is still insufficient in the practical application of agricultural machinery scheduling and allocating. Agricultural machinery scheduling and allocating is relatively complex system engineering. Many factors, such as the level of agricultural mechanization, operating capacity, and operating land, make the scheduling and allocating of agricultural machinery more complex than the general vehicle scheduling and allocating problem. Heilongjiang reclamation area is a representative of modern agriculture. This article aims to conduct research on the internal and cross-regional operations of reclamation, establish a systemic plan for the scheduling and allocating of agricultural machinery in line with the characteristics of modern agriculture and then carry out the practice of agricultural machinery scheduling and allocating more widely.

\section{UNIFIED SCHEDULING AND ALLOCATING MODEL FOR AGRICULTURAL MACHINERY OPERATION}

\subsection{Problem Description}

The coverage rate of agricultural machinery in Heilongjiang reclamation area is close to $100 \%$. With the management area as the basic management unit, agricultural machinery management systems such as unified storage, unified scheduling, unified service, unified use of oil, unified operation quality, and unified fee settlement are implemented for agricultural machinery. Through field surveys, it is found that farmers, in order to maximize their income, after the farm, use the machinery to complete the work required by the region and it can carry out cross-area operations within and between farms. In this way, on the one hand, agricultural machinery can increase the operation area, solve the problem of insufficient mechanical operation, and maximize the income of agricultural machinery households. However, from the practice of cross-regional operations, the current agricultural machinery scheduling and allocating in reclamation areas is mainly based on the path planning and mechanical scheduling and allocating of agricultural machinery households and agricultural machinery managers based on years of agricultural production experience. The overall scheduling and allocating plan is relatively simple and less scientific.

\subsection{Assignment of Assignments}

The task scheduling and allocating problem is a typical combination optimization problem that widely exists in the industrial and agricultural production, transportation, and service industries. The optimization goal of the task scheduling and allocating problem is to determine a reasonable subtask scheduling and allocating plan, so that the total completion time of all tasks is the shortest [7]. The assignment of the operation relationship is based on the prerequisite of the specified time, the specified tasks, and the maximization of the income of the agricultural machinery owner, while shortenning the investment return period. At the same time, in cross-regional operations, the task of operation is for maximizing profit, and it is not required to complete the tasks of all parcels of crossregional operations.

\subsubsection{Decision Variables}

It is supposed that the quantity of agricultural machinery is $N_{\mathrm{V}}$, the quantity of farming blocks in the farm is $N_{\mathrm{F}}$, and the quantity of cross-region operation blocks is $N_{\mathrm{G}}$. The solution of the distribution relationship belongs to the assignment problem in operations research, and the decision variables of the general assignment problem are represented by a $0-1$ matrix [8]. In the assignment problem of job relations, the decision variables are selected as the job assignment relationship of blocks within the farm $X$ and the job assignment relationship of cross-region blocks $Y$, where $X$ is a $0-1$ variable matrix with a dimension of $N_{\mathrm{V}} \times$ $N_{\mathrm{F}}$, and $Y$ is the dimension. It is a $0-1$ variable matrix of $N_{\mathrm{V}}$ $\times N_{\mathrm{G}}$.

$$
\begin{aligned}
& X_{i j}= \begin{cases}0 & \text { Agricultural machinery } i \text { operates on plot } j \\
1 & \begin{array}{l}
\text { Agricultural machinery } i \text { does not operate } \\
\text { on plot } j
\end{array}\end{cases} \\
& \forall i \in\left\{1,2, \ldots, N_{\mathrm{V}}\right\}, j \in\left\{1,2, \ldots, N_{\mathrm{F}}\right\}
\end{aligned}
$$$$
Y_{i j}= \begin{cases}0 & \begin{array}{l}
\text { Agricultural machinery } i \text { operates on cross } \\
\text { regional plot } j
\end{array} \\
1 & \begin{array}{l}
\text { Agricultural machinery } i \text { does not operate } \\
\text { on cross regional plot } j
\end{array}\end{cases}
$$

$\forall i \in\left\{1,2, \ldots, N_{\mathrm{V}}\right\}, j \in\left\{1,2, \ldots, N_{\mathrm{G}}\right\}$ 


\subsubsection{Assumptions}

a) Assumption Condition 1

According to the principle of equal distribution of time dimension, assuming that the operation volume of agricultural machinery on the allocated land is balanced, the operation volume of land within the farm is matrix $Z X$, and the operation volume of cross regional land is matrix $Z Y$.

$$
Z X_{i j}=V_{i} \times X_{i j} \times \frac{F_{j}}{\sum_{k=1}^{N_{\mathrm{V}}}\left(V_{k}+V_{k j}\right)}
$$

$$
Z Y_{i j}=V_{i} \times Y_{i j} \times \frac{G_{j}}{\sum_{k=1}^{N_{\mathrm{V}}}\left(V_{k}+V_{k j}\right)}
$$

Among them:

$Z X_{i j}$ represents the farming quantity of agricultural machinery in the block $\mathrm{j}$ inside the farm, unit: hectares, $\forall i \in\left\{1,2, \ldots, N_{\mathrm{V}}\right\}, j \in\left\{1,2, \ldots, N_{\mathrm{F}}\right\}$;

$Z Y_{i j}$ represents the farming quantity of agricultural machinery in the cross regional block of the farm, unit: hectares, $\forall i \in\left\{1,2, \ldots, N_{\mathrm{V}}\right\}, j \in\left\{1,2, \ldots, N_{\mathrm{G}}\right\}$;

$V_{i}$ is the working efficiency of agricultural machinery, unit: hectares/day, $\forall i \in\left\{1,2, \ldots, N_{\mathrm{V}}\right\}$;

$F_{j}$ is the land area of block $\mathrm{j}$ inside the farm, unit: hectares, $\forall j \in\left\{1,2, \ldots, N_{\mathrm{F}}\right\}$;

$G_{j}$ is the land area of cross-regional block $j$, unit: hectares, $\forall j \in\left\{1,2, \ldots, N_{\mathrm{G}}\right\}$.

b) Assumptions 2:

For the convenience of calculation, it is assumed that after the agricultural machinery completes all block operations in the farm, then the cross region block is selected for operation.

$$
\sum_{i=1}^{N_{\mathrm{V}}} Z Y_{i j}=\left\{\begin{array}{l}
0 \\
G_{j}
\end{array}, \forall j \in\left\{1,2, \ldots, N_{\mathrm{G}}\right\}\right.
$$

\subsubsection{Constraints}

All blocks must be completed within the total working days.

$$
\sum_{i=1}^{N_{\mathrm{V}}} Z X_{i j}=F_{j}, \forall j \in\left\{1,2, \ldots, N_{\mathrm{F}}\right\}
$$

The operation volume of each agricultural machinery in the cross regional plot should be less or equal to the area of the cross regional plot .

$$
\sum_{i=1}^{N_{\mathrm{V}}} Z Y_{i j} \leq G_{j}, \forall j \in\left\{1,2, \ldots, N_{\mathrm{G}}\right\}
$$

The total operation volume of agricultural machinery should be completed within the working days $D$.

$$
\sum_{j=1}^{N_{\mathrm{F}}} Z X_{i j}+\sum_{j=1}^{N_{\mathrm{G}}} Z Y_{i j} \leq V_{i} \times D
$$

\subsubsection{Objective Function}

In order to maximize the total income of agricultural machinery households, the total income includes 3 parts.

Operating income on the farm:

$W_{1}=\sum_{i=1}^{N_{\mathrm{V}}} \sum_{j=1}^{N_{\mathrm{F}}} Z X_{i j} \times R$

Among them, $R$ is the agricultural machinery operating fee (yuan/ha).

Cross-regional revenue:

$W_{2}=\sum_{i=1}^{N_{\mathrm{V}}} \sum_{j=1}^{N_{\mathrm{G}}} Z Y_{i j} \times R$

Transportation costs:

$C=\sum_{i=1}^{N_{\mathrm{V}}} \sum_{j=1}^{N_{\mathrm{F}}} X_{i j} \times 2 R F_{j} \times T+\sum_{i=1}^{N_{\mathrm{V}}} \sum_{j=1}^{N_{\mathrm{G}}} Y_{i j} \times 2 R G_{j} \times T$

Among them, $R F_{j}$ represents the distance from the $\mathrm{jth}$ block in the farm to the agricultural machinery center. $R G_{j}$ is the distance from the $j^{\text {th }}$ block across the region to the agricultural machinery center. $T$ is the transportation cost per unit distance (yuan $/ \mathrm{km}$ ).

Net income:

The objective function is $\operatorname{Max} W$,

$W=W_{1}+W_{2}-C$

\subsection{Path Planning}

After using the model to solve the distribution relationship, the blocks of land that each farmer needs to complete the work in the farm are clarified. Due to the agricultural needs of large-scale blocks during the autumn harvest, the agricultural machinery owner completes the operated plots according to the path planning. After completing one plot, he goes to the next plot until all the allocated plots are completed and returns to the agricultural machinery center. At this moment, cross-regional operations need to re-plan the operation sequence of each agricultural machinery to ensure the shortest transportation path of each agricultural machinery, and thus maximize income [9].

\subsubsection{Decision Variables}

During the operation of agricultural machinery, it needs to go through $\mathrm{n}$ locations from the agricultural 
machinery center to the return to the agricultural machinery center, so that the decision variables are $X$ and $u$, where:

$X_{i j}= \begin{cases}0 & \begin{array}{l}\text { Agricultural machinery does not run } \\ \text { from point } i \text { to point } j\end{array} \\ 1 & \begin{array}{l}\text { Agricultural machinery runs from pint } \\ i \text { to point } j\end{array}\end{cases}$

$\forall i \in\{1,2, \ldots, n\}, j \in\{1,2, \ldots, n\}$

$u_{i}$ represents the serial mumber of agricultural

machinery,

$u_{i} \in\{1,2, \ldots, n\}, \forall i \in\{1,2, \ldots, n\}$

\subsubsection{Constraints}

Agricultural machinery starts from all points once, and all points are reached once. All points are connected to form a ring, and no sub-rings appear.

$$
\begin{aligned}
& \sum_{j=1}^{n} X_{i j}=1, \forall i \in\{1,2, \ldots, n\} \\
& \sum_{i=1}^{n} X_{i j}=1, \forall j \in\{1,2, \ldots, n\} \\
& u_{i}-u_{j}+(n-1) \times X_{i j} \leq n-2, \forall i, j \in\{2,3, \ldots, n\}
\end{aligned}
$$

\subsubsection{Objective Function}

The objective function is to minimize the distance, $c_{i j}$ is the distance from site $i$ to site $j$.

The minimum distance is:

$$
\min \sum_{i=1}^{n} \sum_{j=1}^{n} X_{i j} \times c_{i j}, \forall i, j \in\{1,2, \ldots, n\}
$$

\section{INTRODUCTION OF TEACHING AND LEARNING OPTIMIZATION ALGORITHM}

Teaching-Learning-Based Optimization (TLBO) is a new swarm intelligence optimization algorithm proposed by Rao et al. in 2010. It is a new algorithm proposed after genetic algorithm, ant colony algorithm, and particle swarm algorithm [9, 10]. A new swarm intelligence algorithm can be used to solve complex multi-objective problems [11]. It simulates the teaching process of the teacher to the students and the learning process of the students, and the purpose is to improve the student's academic performance through the "teaching" of the teacher and the mutual "learning" between the students. TLBO algorithm has few parameters, simple algorithm, is easy to understand, fast solving speed, high precision and strong convergence ability [12]. Due to the outstanding optimization performance of the TLBO algorithm, it has attracted the attention of many scholars in the short time since it was proposed. It has been widely used in many fields, further reflecting its scientific research and practical value, and has mainly been applied to clustering problems, sequence pattern discovery problems, multi-objective optimization problems, etc. [13].

\subsection{Algorithm Description}

The optimization algorithm based on "teaching and learning" simulates the learning method of the class as a unit [14]. The improvement of the level of students in the class needs to be guided by the teacher's "teaching", and at the same time, the students need to "learn" from each other to promote the absorption of knowledge. Among them, teachers and students are equivalent to the individuals in the evolutionary algorithm, and the teachers are the individuals with the best fitness value. TLBO is initialized as a group of random students, which can be regarded as a class, each student represents the current value of a solution in the search process, and then iteratively finds the optimal solution. In each iteration, students update themselves in two steps. The first step is to update yourself by learning from the student with the best current fitness value in the class, that is, the "teacher". This step can be called "teaching". The second step is to randomly select a student in the class and decide whether to learn directly from him or to study in the opposite direction by comparing with the current fitness value. This step is called "learning". The update formula is as follows.

In the teaching stage, the teacher $x_{\mathrm{T}}$ is the current solution with the best fitness value in a class. $x_{M}$ is the average of each student's current solution in this class. Learners try to improve their average grades through teachers' teaching. For the $i^{\text {th }}$ learner $x_{i}$, the updated formula is:

new $x_{i}=x_{i}+\operatorname{rand} \times\left(x_{\mathrm{T}}-T_{\mathrm{F}} \times x_{\mathrm{M}}\right)$

Among them, rand is a random digit generated among $[0,1], T_{\mathrm{F}}$ represents the degree of this learning, and the formula is as follows.

$T_{\mathrm{F}}=\operatorname{round}(1-\operatorname{rand}(0,1))$

In the learning phase, each learner improves his grades by interacting with learners randomly selected from the classroom. The calculation is as follows:

new $x_{i}=\left\{\begin{array}{l}x_{i}+\operatorname{rand} \times\left(x_{i}-x_{j}\right), f\left(x_{i}\right)<f\left(x_{j}\right) \\ x_{i}+\operatorname{rand} \times\left(x_{j}-x_{i}\right), f\left(x_{i}\right) \geq f\left(x_{j}\right)\end{array}\right.$

Among them, $x_{i}$ is the result of updating from the "teaching" stage, $j$ is randomly selected from the population, and $f()$ represents the fitness value.

\subsection{Algorithm Flow}

Initialize the class, each student in the class $x_{i},(i=1$, $\left.2, \ldots, N_{\mathrm{P}}\right)$ is randomly generated in the search space.

In the "teaching" stage, each student $x_{i}$ in the class learns according to the difference between $x_{\mathrm{T}}$ and the student's average value $x_{\mathrm{M}}$.

"Teaching" updates, each student compares the results after learning with the results before learning in the "teaching" stage; if the results after learning are better than the results before learning, then update, and otherwise it will not have to be updated. 
In the "learning" stage, each student $x_{j}$ in the class randomly selects a learning object $x_{j}$ in the class, and learns by analyzing the fitness difference between $x_{i}$ and $x_{j}$.

"Learning" update, each student compares the results after learning with the results before learning in the "teaching" phase; if the results after learning are better than those before learning, update them, otherwise they will not have to be updated.

If the end condition is met, the iteration ends, otherwise go to b) to continue the iteration [15].

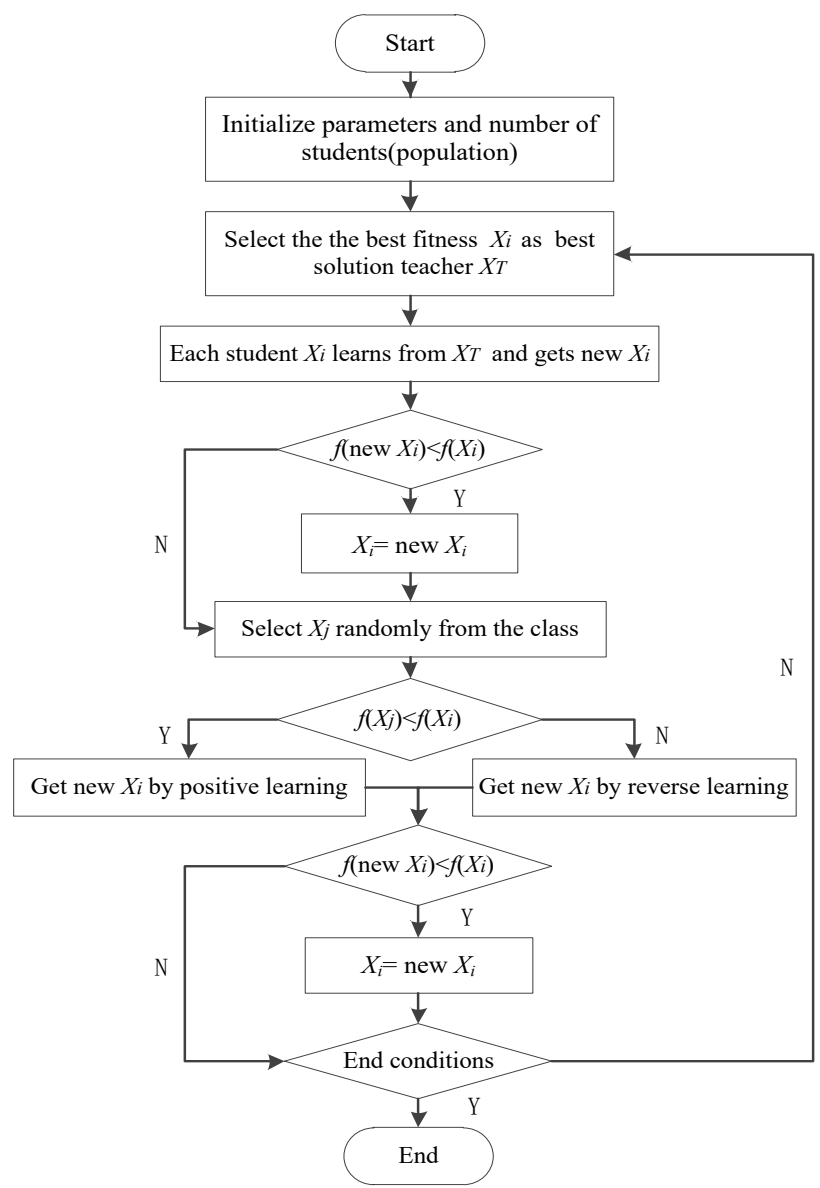

Figure 1 The TLBO flow

\subsection{Algorithm Improvement}

If the decision variable is $0-1$, first make the decision variable continuous and generate it randomly during initialization [16]. The initialization form of the formula is:

$x=$ rand -0.5

In the fitness calculation, it is mapped to 0 or 1 , the formula is as follows.

$x=\left\{\begin{array}{l}0, x \leq 0 \\ 1, x>0\end{array}\right.$

In the iterative process, the decision variables have been kept in a continuous form, and only become $0-1$ form during fitness calculation.

\section{TEST DATA PREPARATION}

This paper takes the autumn harvest data of soybean in Jianshan farm of Heilongjiang reclamation area as an example. The information of blocks in the farm, the information of cross-regional blocks, and the ability of agricultural machinery are shown in Tab. 1, Tab. 2 and Tab. 3 below. Other information includes total workable time, etc.

\begin{tabular}{|c|c|c|c|c|}
\hline Block Number & $\begin{array}{l}\text { Longitude } \\
\text { / degrees }\end{array}$ & $\begin{array}{c}\text { Latitude / } \\
\text { degrees }\end{array}$ & $\begin{array}{l}\text { Height } \\
/ \mathrm{m}\end{array}$ & $\begin{array}{c}\text { Planting area } \\
\text { / hectares }\end{array}$ \\
\hline 1 & 125.4102 & 48.79667 & 0 & 67.6 \\
\hline 2 & 125.5035 & 48.84437 & 0 & 59.6 \\
\hline 3 & 125.5095 & 48.83857 & 0 & 258.5 \\
\hline 4 & 125.5289 & 48.83655 & 0 & 63.9 \\
\hline 5 & 125.5448 & 48.84006 & 0 & 298.4 \\
\hline 6 & 125.4441 & 48.91638 & 0 & 313.3 \\
\hline 7 & 125.4484 & 48.92742 & 0 & 239.9 \\
\hline 8 & 125.4276 & 48.82983 & 0 & 473.7 \\
\hline 9 & 125.4026 & 48.82912 & 0 & 379.0 \\
\hline 10 & 125.4383 & 48.84173 & 0 & 137.4 \\
\hline 11 & 125.4733 & 48.90937 & 0 & 172.7 \\
\hline $\begin{array}{c}\text { Agricultural } \\
\text { Machinery Center }\end{array}$ & 125.4361 & 48.8806 & 0 & - \\
\hline
\end{tabular}

Table 2 Cross regional block data

\begin{tabular}{|c|c|c|c|c|}
\hline $\begin{array}{c}\text { Block } \\
\text { Number }\end{array}$ & $\begin{array}{c}\text { Longitude } / \\
\text { degrees }\end{array}$ & $\begin{array}{c}\text { Latitude } / \\
\text { degrees }\end{array}$ & Height / m & $\begin{array}{c}\text { Planting area } \\
\text { / hectares }\end{array}$ \\
\hline 1 & 124.27 & 48.21819 & 0 & 1507 \\
\hline 2 & 125.8756 & 48.03694 & 0 & 153 \\
\hline 3 & 124.505 & 48.47839 & 0 & 300 \\
\hline 4 & 123.6722 & 48.48256 & 0 & 1000 \\
\hline 5 & 124.884 & 48.48419 & 0 & 267 \\
\hline 6 & 126.3123 & 49.38355 & 0 & 200 \\
\hline 7 & 124.51265 & 49.26472 & 0 & 393 \\
\hline 8 & 124.14366 & 49.03287 & 0 & 413 \\
\hline 9 & 124.25437 & 48.82145 & 0 & 327 \\
\hline
\end{tabular}

Table 3 Data of agricultural machinery operation

\begin{tabular}{|c|c|c|c|}
\hline $\begin{array}{c}\text { Agricultural } \\
\text { Machinery } \\
\text { Number }\end{array}$ & $\begin{array}{c}\text { Operating speed } \\
\text { / ha/day }\end{array}$ & $\begin{array}{c}\text { Operation fee / } \\
\text { yuan/ha }\end{array}$ & $\begin{array}{c}\text { Transportation } \\
\text { cost / yuan/km }\end{array}$ \\
\hline $1-5$ & 80 & 315 & 10 \\
\hline $6-7$ & 120 & 315 & 10 \\
\hline
\end{tabular}

Note: Two models are selected, 5 John Deere S660 grain combine harvesters and 2 S680 grain combine harvesters, with operating capacities of 80 hectares/20 hours and 120 hectares/20 hours respectively.

\section{RESULTS AND ANALYSIS}

According to the teaching and learning algorithm, the calculation program is compiled and the data is substituted into the calculation. In order to obtain the solution effect of the algorithm to the problem, the program is run repeatedly, the maximum number of iterations is 2000 times, a total of 5 runs, and the single run time is about 350 $\mathrm{s}$, the running time and final results of the program are statistically as follows:

\begin{tabular}{|c|c|c|c|c|c|c|c|}
\hline & 1 & 2 & 3 & 4 & 5 & $\begin{array}{l}\text { Mean } \\
\text { value }\end{array}$ & $\begin{array}{c}\text { Optimal } \\
\text { value }\end{array}$ \\
\hline $\begin{array}{c}\text { Results / } \\
\text { thousand } \\
\text { yuan }\end{array}$ & 2061 & 1967 & 2075 & 2043 & 1996 & 20284 & 2075 \\
\hline $\begin{array}{l}\text { Convergence } \\
\text { rate / times }\end{array}$ & 1018 & 1879 & 404 & 81 & 1623 & 1001 & 1879 \\
\hline
\end{tabular}




\subsection{Convergence of Objective Function}

Under the solution of the TLBO algorithm, the objective function converges faster, and a satisfactory solution is obtained.

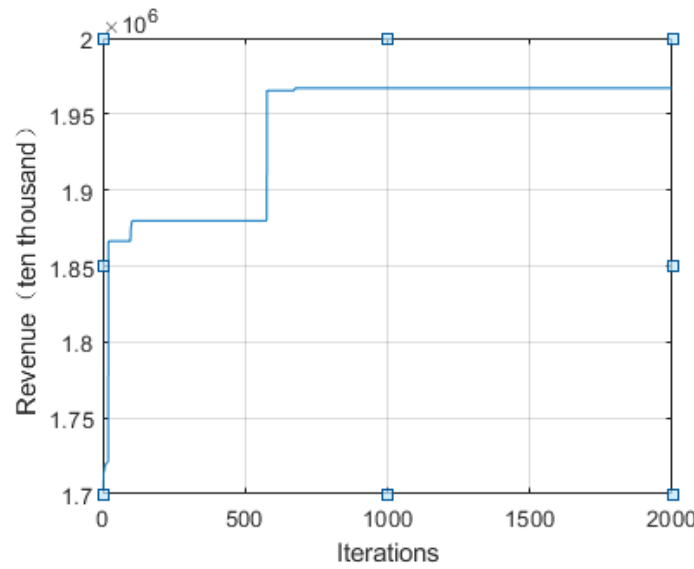

Figure 2 Convergence of scheduling and allocating solution for objective function

Table 5 Distribution relationship of agricultural machinery operation in the farm Unit: hectare

\begin{tabular}{|c|c|c|c|c|c|c|c|c|c|c|c|}
\hline \multirow{2}{*}{$\begin{array}{c}\text { Agricultural } \\
\text { machinery }\end{array}$} & \multicolumn{10}{|c|}{ Block } \\
\cline { 2 - 14 } & 1 & 2 & 3 & 4 & 5 & 6 & 7 & 8 & 9 & 10 & 11 \\
\hline 1 & 0 & 0 & 1 & 1 & 0 & 1 & 1 & 1 & 0 & 1 & 1 \\
\hline 2 & 1 & 0 & 1 & 0 & 1 & 1 & 1 & 1 & 1 & 0 & 1 \\
\hline 3 & 0 & 0 & 0 & 1 & 0 & 1 & 0 & 1 & 0 & 1 & 0 \\
\hline 4 & 1 & 1 & 1 & 1 & 1 & 1 & 0 & 1 & 1 & 0 & 1 \\
\hline 5 & 1 & 1 & 1 & 0 & 0 & 1 & 1 & 1 & 1 & 0 & 1 \\
\hline 6 & 1 & 0 & 0 & 0 & 0 & 0 & 1 & 1 & 1 & 0 & 0 \\
\hline 7 & 1 & 1 & 0 & 1 & 0 & 0 & 0 & 1 & 1 & 0 & 1 \\
\hline
\end{tabular}

Table 6 Distribution relationship of cross regional agricultural machinery operation Unit: hectare

\begin{tabular}{|c|c|c|c|c|c|c|c|c|c|}
\hline \multirow{2}{*}{$\begin{array}{c}\text { Agricultural } \\
\text { machinery }\end{array}$} & \multicolumn{10}{|c|}{ Block } \\
\cline { 2 - 11 } & 1 & 2 & 3 & 4 & 5 & 6 & 7 & 8 & 9 \\
\hline 1 & 1 & 0 & 0 & 0 & 1 & 0 & 1 & 1 & 0 \\
\hline 2 & 1 & 0 & 0 & 0 & 0 & 0 & 0 & 1 & 0 \\
\hline 3 & 0 & 0 & 1 & 1 & 1 & 1 & 1 & 0 & 0 \\
\hline 4 & 0 & 1 & 1 & 0 & 0 & 1 & 1 & 0 & 0 \\
\hline 5 & 1 & 1 & 1 & 0 & 1 & 0 & 1 & 0 & 0 \\
\hline 6 & 1 & 0 & 0 & 1 & 0 & 0 & 1 & 1 & 0 \\
\hline 7 & 1 & 1 & 1 & 1 & 0 & 0 & 1 & 0 & 0 \\
\hline
\end{tabular}

Table 7 Operating area of agricultural machinery in the farm Unit: hectare

\begin{tabular}{|c|c|c|c|c|c|c|c|c|c|c|c|}
\hline \multirow{2}{*}{$\begin{array}{c}\text { Agricultural } \\
\text { machinery }\end{array}$} & \multicolumn{10}{|c|}{ Block } \\
\cline { 2 - 15 } & 1 & 2 & 3 & 4 & 5 & 6 & 7 & 8 & 9 & 10 & 11 \\
\hline 1 & 0 & 0 & 65 & 14 & 0 & 63 & 53 & 59 & 0 & 69 & 31 \\
\hline 2 & 11 & 0 & 65 & 0 & 149 & 63 & 53 & 59 & 63 & 0 & 31 \\
\hline 3 & 0 & 0 & 0 & 14 & 0 & 63 & 0 & 59 & 0 & 69 & 0 \\
\hline 4 & 11 & 17 & 65 & 14 & 149 & 63 & 0 & 59 & 63 & 0 & 31 \\
\hline 5 & 11 & 17 & 65 & 0 & 0 & 63 & 53 & 59 & 63 & 0 & 31 \\
\hline 6 & 17 & 0 & 0 & 0 & 0 & 0 & 80 & 89 & 95 & 0 & 0 \\
\hline 7 & 17 & 26 & 0 & 21 & 0 & 0 & 0 & 89 & 95 & 0 & 47 \\
\hline
\end{tabular}

Table 8 Trans regional agricultural machinery operation volume Unit: hectare

\begin{tabular}{|c|c|c|c|c|c|c|c|c|c|}
\hline $\begin{array}{c}\text { Agricultural } \\
\text { machinery }\end{array}$ & \multicolumn{1}{|c|}{ Block } \\
\cline { 2 - 11 } & 251 & 0 & 0 & 0 & 89 & 0 & 56 & 118 & 0 \\
\hline 1 & 251 & 0 & 0 & 0 & 0 & 0 & 0 & 118 & 0 \\
\hline 2 & 0 & 0 & 67 & 250 & 89 & 100 & 56 & 0 & 0 \\
\hline 3 & 0 & 44 & 67 & 0 & 0 & 100 & 56 & 0 & 0 \\
\hline 4 & 251 & 44 & 67 & 0 & 89 & 0 & 56 & 0 & 0 \\
\hline 5 & 377 & 0 & 0 & 375 & 0 & 0 & 84 & 177 & 0 \\
\hline 6 & 377 & 66 & 100 & 375 & 0 & 0 & 84 & 0 & 0 \\
\hline 7 & & &
\end{tabular}

\subsection{Path Planning}

In the unified scheduling and allocating mode in the field and across districts, the distribution relations of agricultural machinery and block operations on the farm solved by the teaching and learning algorithm are shown in Tab. 5 and Tab. 6. The "starting point" in the figure is the center of the agricultural machinery, and the "end point" is the block of the last operation of the agricultural machinery in the allocated blocks. The path diagram is shown in Fig. 3.

Agricultural machinery driving path:

No.1 agricultural machinery leaves the agricultural machinery center, and passes through local field block 11 , local field block 6 , local field block 7, the outfield block 7 , the outfield block 8 , the outfield block 1 , the outfield block 5 , the local field Block 8, local field block 10, local field block 3 , local field block 4 . Finally, it returns to the center and drives $340.4 \mathrm{~km}$.

No. 2 agricultural machinery leaves the center and passes through the local field block 5, the local field block 3 , the local field block 8 , the local field block 9 , the local field block 1, the outfield block 1, the outfield block 8 , and the local field block 7, local field block 6, local field block 11. Finally, it returns to the center and drives $324.4 \mathrm{~km}$.

No. 3 agricultural machinery leaves the agricultural machinery center and passes through local field block 4 , local field block 10, local field block 8 , the outfield block 5 , the outfield block 3 , the outfield block 4 , the outfield block 7 , and the outfield block 6 , then the local field block 6 . Finally, it returns to the center and drives $485.7 \mathrm{~km}$.

No. 4 agricultural machinery leaves the agricultural machinery center and passes through local field block 6 , local field block 11 , the outfield block 6 , the outfield block 7 , the outfield block 3 , the outfield block 2, the local field block 5, and the local field Block 4, local field block 3, local field block 2, local field block 1 . Finally, it returns to the center and drives $534.6 \mathrm{~km}$.

No.5 agricultural machinery leaves the agricultural machinery center and passes through local field block 11 , local field block 6, local field block 7, the outfield block 7, the outfield block 3 , the outfield block 1 , the outfield block 5 , the outfield block 2 , the local field block 1 , the local field block 9 , the local field block 8 , the local field block 3 , and the local field block 2 . Finally, it returns to the center and drives $460 \mathrm{~km}$.

No. 6 agricultural machinery leaves the agricultural machinery center and passes through local field block 8 , local field block 9, local field block 1, the outfield block 1 , the outfield block 4 , the outfield block 8 , the outfield block 7, the local field block 7. Finally, it returns to the center and drives $361.2 \mathrm{~km}$.

No. 7 agricultural machinery leaves the agricultural machinery center and passes through local field block 11, local field block 2, local field block 4, the outfield block 2, the outfield block 3 , the outfield block 1 , the outfield block 4 , the outfield block 7 , local field block 9 , local field block 1 , local field block 8 . Finally, it returns to the center and drives $507.2 \mathrm{~km}$. 

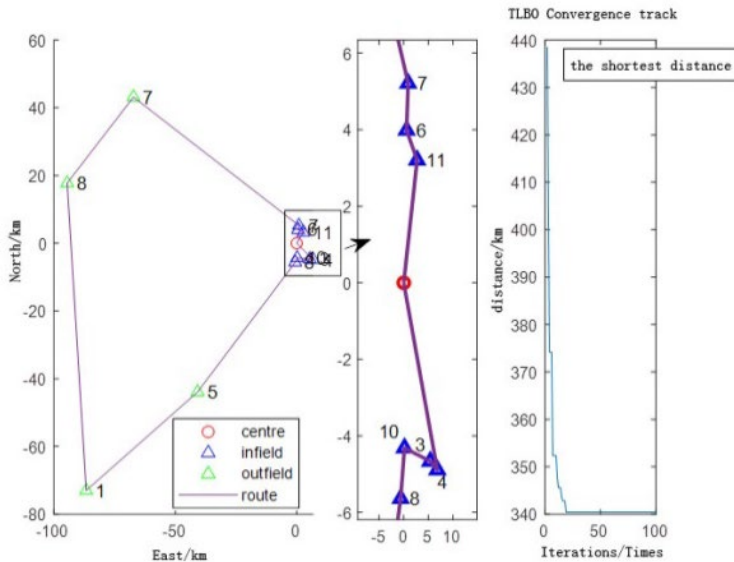

(a) No 1 Agriculture machinery operation route
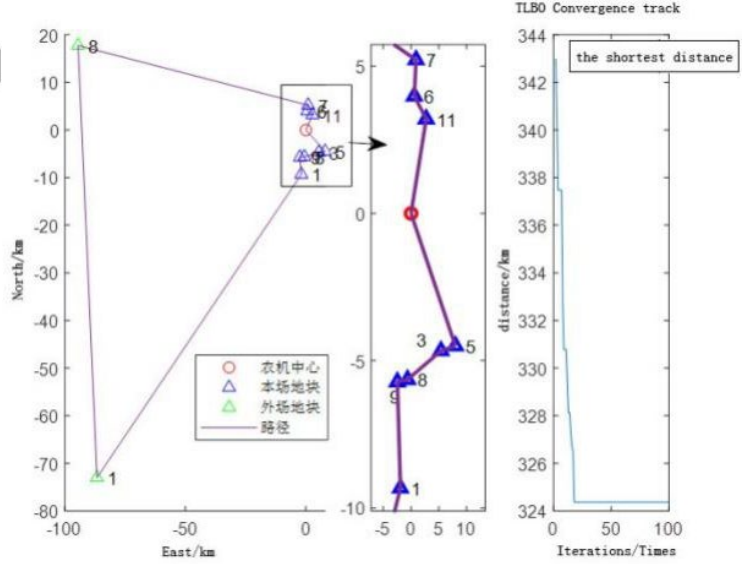

(b) No 2 Agriculture machinery operation route
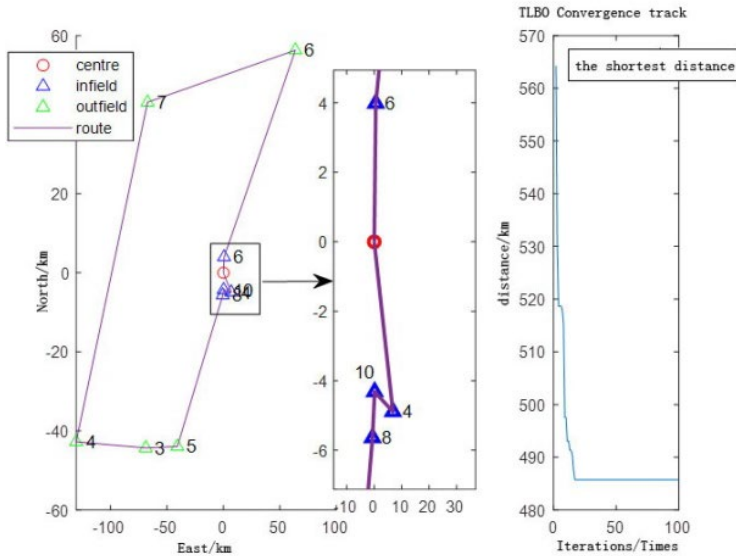

(c) No 3 Agriculture machinery operation route
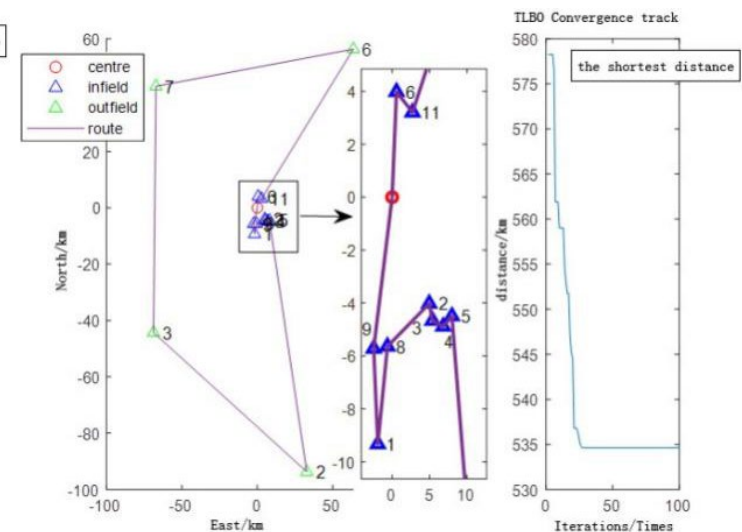

(d) No 4 Agriculture machinery operation route

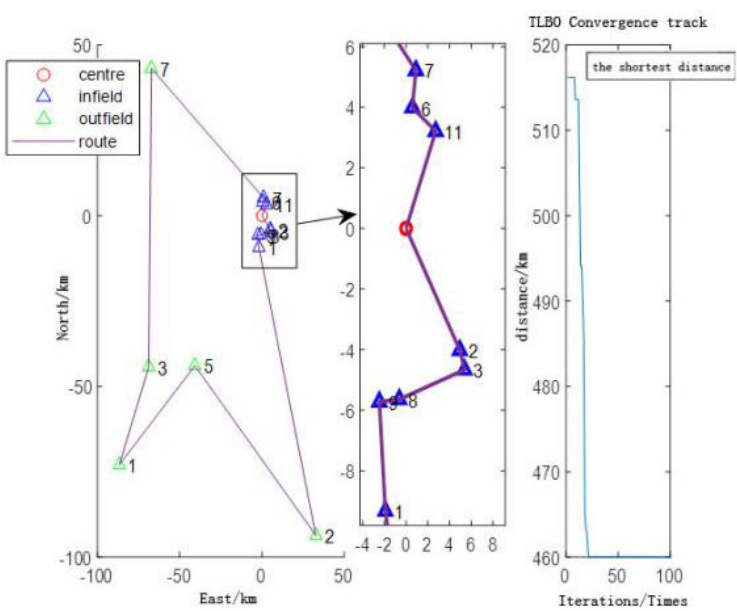

(e) No 5 Agriculture machinery operation route

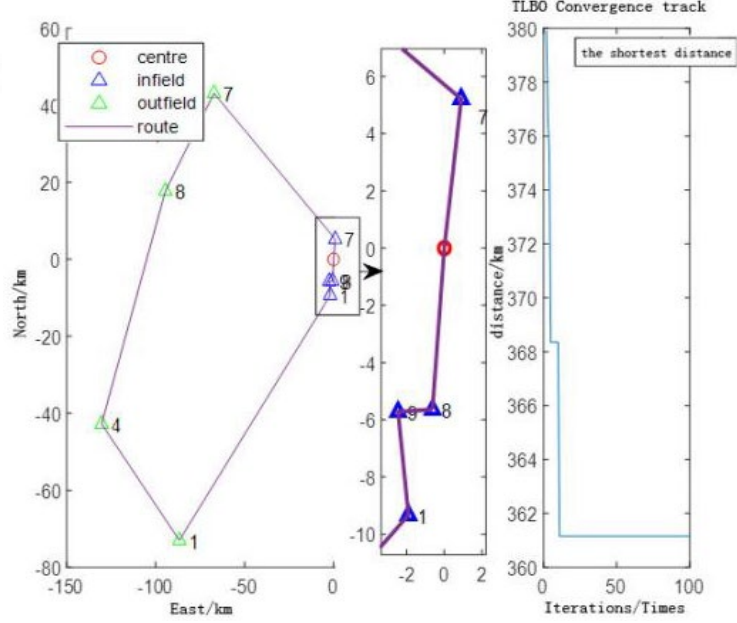

(f) No 6 Agriculture machinery operation route

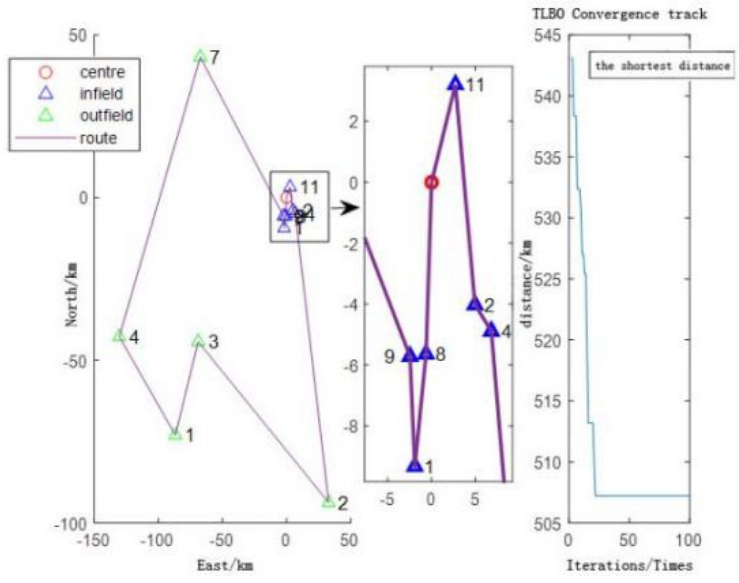

(g)No 7 Agriculture machinery operation route

Figure 3 No 1- No 7 Agricultural machinery operation route 


\section{CONCLUSION}

By introducing the 0-1 mapping relationship, the teaching and learning optimization algorithm can solve the discrete problem of agricultural machinery allocation. Taking the maximum income of agricultural machinery households and the shortest allocation path of agricultural machinery as the goal, the model is established and solved by using the teaching and learning optimization algorithm. It realizes the unified allocation in and out of the farm in the process of agricultural machinery harvesting soybean. The algorithm realizes the optimal operation path of agricultural machinery, which has good global search and fast convergence speed. It obtains satisfactory results of operation relationship allocation and path planning, and makes it more scientific for agricultural machinery users to choose the operation path.

\section{Acknowledgments}

The work is supported by Heilongjiang Province Philosophy and Social Science Research Planning Project (19JYB023).Agricultural Legal System Construction and Policy Research Project by Ministry of Agriculture of the People's Republic of China (15162130112022).

\section{REFERENCES}

[1] Sorensen, C. G. \& Bochtis, D. (2010). Agricultrral fleet management: a systems approach. XVII ${ }^{\text {th }}$ World Congress of the International Commission of Agricultural Engineering (CIGR).

[2] Sethanan, K. \& Neungmatcha, W. (2016). Multi-objective particle swarm optimization for mechanical harvester route planning of sugarcane field operations. European Journal of Operational Research, 252(2), 969-984. https://doi.org/10.1016/j.ejor.2016.01.043

[3] Yao, J., Liu, J., Zhang, F., et al. Research on optimization of agricultural machinery operation path based on Doppler and greedy strategy. Chinese Journal of Agricultural Machinery Chemistry, 41(4), 8.

[4] Cao, H., Li, H., Lv, J., et al. (2020). Design of Agricultural Machinery Dispatching Management System-Based on the Stadium Smart Property Management System. Research on Agricultural Mechanization, 42(6), 220-223, 229.

[5] Ma, Q. (2006). Research on Dynamic Task Allocation Based on Multi-Agent System. Huazhong University of Science and Technology.

[6] Liu, L., Chen, T., Gao, S., Liu, Y., Yang, S. \& Wang, X. (2021). Optimization of Agricultural Machinery Allocation in Heilongjiang Reclamation Area Based on Particle Swarm Optimization Algorithm. Tehnički vjesnik, 28(6), 1885-1893. https://doi.org/10.17559/TV-20210427163416

[7] Wang, X. (2015). Research on agricultural machinery scheduling problem based on machine-improved heuristic search algorithm. Information System Engineering, 2015(9), 109.

[8] Hu, Y. (2005). Operational Research Course. Beijing: Tsinghua University Press.

[9] Zhu, X., Ding, Y., Cai, X., Wang, H., \& Zhang, X. (2017). Optimal schedule for agricultural machinery using an improved Immune-Tabu Search Algorithm. The $36^{\text {th }}$ Chinese Control Conference (CCC), 2824-2829. https://doi.org/10.23919/ChiCC.2017.8027793

[10] Chen, Y. (2012). Optimal agricultural machinery collaborative harvesting scheduling method and system. CN201210541633.4A. Shanghai Agricultural Information
Co., Ltd.

[11] Rao, R. V., Savsani, V. J., \&Vakharia, D. P. (2011). Teaching-learning-based optimization: A novel method for constrained mechanical design optimization problems. ComputerAided Design, 43(3), 303-315. https://doi.org/10.1016/j.cad.2010.12.015

[12] Rao, R. V., Savsani, V. J., \& Balic, J. (2012). Teachinglearning-based optimization algorithm for unconstrained and constrained real-parameter optimization problems. EngineeringOptimization, 44(12), 1447-1462. https://doi.org/10.1080/0305215X.2011.652103

[13] Crepinsek, M., Liu, S. H., \& Mernik, L. (2012). A note on teaching-learning-based optimization algorithm. Information Sciences, 212, 79-93. https://doi.org/10.1016/j.ins.2012.05.009

[14] Rao, R. V. \& Pawar, P. J. (2013). Parameter optimisation of modern maching processes using teaching-learning-based optimisation algorithm. Eng. Appl. Artif. Intell., 67, 9951006. https://doi.org/10.1007/s00170-012-4524-2

[15] Rao, R. V., Savsani, V. J., \& Vakharia, D. P. (2012). Teaching-learning-based optimization: An optimization method for continuous non-linear large scale problems. Information Sciences, 183, 1-15. https://doi.org/10.1016/j.ins.2011.08.006

[16] Xing, W. (2017). The complexity concept of discrete optimization and continuous optimization. Journal of Operations Research, 21(2), 39-45.

\section{Contact information:}

Ye LIU

Heilongjiang Bayi Agricultural University,

Xinyang Road, Longfeng,

Daqing, Heilongjiang 163319, China

Luan SHI

Heilongjiang Polytechnic,

Harbin, Heilongjiang 150070, China

\section{Yang GAO}

Daqing Huake Co., Ltd. Daqing,

Heilongjiang 163316, China

\section{Chunyu KOU}

Beidahuang Group Co., Ltd. Harbin, Heilongjiang 150030, China

\section{Shuguo YANG}

College of Economics and Management, Heilongjiang Bayi Agricultural University, Xinyang Road, Longfeng,

Daqing, Heilongjiang 163319, China

Li LIU

(Corresponding author)

Heilongjiang Northeast Petroleum University Science Park Development Co.,

Ltd, Daqing, Heilongjiang 163001, China

Heilongjiang Bayi Agricultural University,

Daqing, Heilongjiang 163319, China

Email: ndliuli@163.com 